\title{
A SITUAÇÃO DA CLASSE TRABALHADORA MIGRANTE
}

\section{LA SITUACIÓN DE LA CLASE TRABAJADORA MIGRANTE}

\section{THE SITUATION OF THE MIGRANT WORKING CLASS}

DOI: $\underline{\text { http://dx.doi.org/10.9771/gmed.v11i2.32620 }}$

\author{
Janaina Gulart Oliveira Queiroz
}

Célia Regina Vendramini²

Resumo: O artigo aborda a produção e reprodução da vida de migrantes nordestinos da construção civil que trabalham no Campus central da Universidade Federal de Santa Catarina - UFSC. O objetivo principal é analisar a produção e reprodução da vida de trabalhadores migrantes no contexto das migrações na sociedade capitalista. Três aspectos são abordados, as relações e condições de trabalho, as condições de vida e a escolarização dos migrantes.

Palavras-chave: Migração; Classe trabalhadora; Trabalho; Escola.

Resumen: El artículo aborda la producción y reproducción de la vida de migrantes de la construcción civil que trabajan en el Campus central de la Universidad Federal de Santa Catarina- UFSC. El Objetivo principal es analizar la producción y reproducción de la vida de trabajadores migrantes en el contexto de las migraciones en la sociedad capitalista. Tres aspectos son estudiados, las relaciones y condiciones de y trabajo, las condiciones de vida y la escolarización de los migrantes.

Palabras clave: Migración, Clase trabajadora, Trabajo, Escuela.

Abstract: The article refers to the production and reproduction of the life of migrants from northeastern part of Brazil working at the construction industry inside central campus of Universidade Federal de Santa Catarina - UFSC. The main objective is to analyze the production and reproduction of life by temporary migrant workers in the context of migrations in the capitalist society. Three aspects are addressed, relations and working conditions, living conditions and schooling of migrants.

Keywords: Migration; Working class; Labor; School.

\section{Introdução}

O propósito do artigo é apresentar e refletir sobre as condições de vida, trabalho e escolarização de migrantes nordestinos da construção civil. Estes são expostos à exploração no trabalho, rebaixamento dos direitos trabalhistas e longas e exaustivas jornadas de trabalho, em associação com as péssimas condições de moradia (barracos insalubres) e alimentação irregular. Além disso, apresentam baixa escolarização e todos abandonaram a escola em função do trabalho. Tal situação se assemelha às condições de vida do operariado inglês no século XIX, analisadas por Engels (2008) na obra $A$ situação da classe trabalhadora na Inglaterra.

As análises aqui apresentadas têm como base pesquisa desenvolvida com migrantes temporários nordestinos da construção civil que trabalhavam no Campus principal da Universidade Federal de Santa Catarina (UFSC), em Florianópolis/SC, com o objetivo de compreender a produção e reprodução da vida 
dos trabalhadores. Na coleta de dados foram realizadas um total de 14 entrevistas $(9$ com trabalhadores temporários e 5 com funcionários das empresas) em dois canteiros de obras de duas empresas que prestam serviço na Universidade. O canteiro de obras é local de trabalho e também de moradia, o que possibilitou acompanhar o cotidiano dos trabalhadores e suas condições de trabalho, moradia, alimentação e o restrito "tempo livre" que lhes sobra.

O estudo teve como foco as migrações internas, particularmente as saídas dos trabalhadores do Nordeste para o Sul do Brasil. Compreende- se que o processo de migração é constante e na atualidade tem-se acelerado. O capital para seguir acumulando (processo contraditório de expansão e concentração) continua expropriando e explorando a classe trabalhadora. São grandes massas de pessoas que se deslocam internamente para a produção social da vida e ficam sujeitos a condições de pobreza, ocupados em trabalhos simples e irregulares. Os trabalhadores migrantes temporários da construção civil em Florianópolis compõem, nos termos de Marx (2011), uma população excedente, presente desde a origem do modo de produção capitalista e necessária no seu processo de acumulação.

Os trabalhadores por nós entrevistados são migrantes temporários, cujas trajetórias de vida são marcadas pela constante mobilidade, migram para trabalhar em uma região por um determinado período e depois retornam para seus locais de origem. Muitas vezes reproduzem a situação de "migrante permanentemente temporário", pois repetem o ciclo inúmeras vezes ou por toda a vida (SILVA, 1992, p. 166). $89 \%$ deles são oriundos do estado da Bahia e $11 \%$ do estado de Pernambuco. São homens, de origem pobre, com pouca ou nenhuma escolaridade, na faixa etária de 20 a 39 anos. Deste total, 67\% são de etnia negra, $11 \%$ pardos e $22 \%$ brancos, $89 \%$ são solteiros e $11 \%$ casados.

\section{As relações e condições de trabalho}

As reflexões aqui apresentadas expressam as contradições em torno da relação capital trabalho. De um lado, uma massa de trabalhadores expropriada das condições de produção da vida e, portanto, completamente disponível para ser explorada, em qualquer lugar e a qualquer preço. De outro lado, empresas capitalistas que encontram uma força de trabalho de baixo custo, longe da família e amigos, portanto com todo o tempo disponível para o trabalho, além de desorganizada em termos sindicais e dócil. E temos ainda a presença do Estado que regula contratos temporários, flexíveis e informais, e não age na fiscalização do descumprimento dos direitos trabalhistas. Constituem-se assim as condições propícias para a acumulação do capital e a exploração do trabalhador.

As empresas da construção civil e terceirizadas que prestam serviço na universidade trabalham com contratos flexíveis e precários, os quais caracterizam os "modos de ser da informalidade", nos termos de Antunes (2015), desconsiderando os direitos e a regulamentação social protetora do trabalho. De acordo com Harvey (2014, p. 105), há "uma forte tendência sistêmica das empresas capitalistas de lançar mão da terceirização, presumivelmente para chegar a uma definição muito mais 'eficiente' do trabalho coletivo empregado por elas, incrementando com isso sua taxa individual de lucro". 
Quando perguntadas sobre porque contratam trabalhadores migrantes, as empresas esclarecem que estes, além de constituírem força de trabalho barata, disponibilizam todo o seu tempo para o trabalho e não fazem muitas exigências.

São eles que vem... Eles vem para cá, porque tem várias empresas aqui no campus, então eles batem ali, batem aqui, batem em todas as obras. Então eles vem de obra em obra [...] dizem que estão precisando de emprego, aí a gente pega, olha a carteira, olha o currículo, faz algumas perguntas. Hum, eles vem com empenho, né! Eles vem para trabalhar, eles são uma mão de obra um pouco mais barata e são bem educados. No contexto geral é que eles são bons trabalhadores, trabalham bem (grifo nosso).3

A gente gosta muito desse pessoal que vem de longe, porque eles são bem mandados, a gente pode pedir para eles fazerem o que for, eles vão fazer sem fazer bico, sem reclamar. Obedientes também (grifo nosso).4

Como não poderia ser diferente numa relação antagônica entre capital e trabalho, não há consenso sobre o cumprimento da legislação trabalhista, a jornada de trabalho, horas extras, entre outros aspectos. As empresas afirmam que cumprem rigorosamente a legislação, que a carga horária de trabalho concentra-se nos limites da legislação trabalhista e que seguem os critérios estabelecidos pela NR18 (Norma Regulamentadora das Condições e Meio Ambiente de Trabalho na Indústria da Construção).

Da parte dos trabalhadores, estes reclamam que alguns direitos não são cumpridos pelas empresas, relacionados a contrato, jornada de trabalho, horas extras, férias etc. Observamos que os trabalhadores realizam jornadas diárias de até 14 horas e trabalham aos sábados até às 21 horas e aos domingos pela manhã. Devido aos baixos salários, eles buscam nas horas extras uma melhoria no rendimento. Além disso, relevam que são incentivados pelas empresas a aumentar a carga horária de trabalho. Os depoimentos abaixo apresentam alguns dos aspectos aqui assinalados.

Aqui? Acho que não. Contrato não tem um determinado aí. (Risos) Quer dizer nós tá fichado, mas contrato mesmo, não tem de validade.

Trabalho de sábado a domingo. Sábado eu tenho que trabalhar para ganhar o dia, o domingo, trabalha meio dia e só paga meio dia. Dá 14 horas num dia, por dia. Sábado nós trabalhamos até as seis. Sim, e domingo era para ganhar o dia e só paga meio dia. ${ }^{5}$

Visando maior produtividade e lucro, e diante da necessidade dos trabalhadores de estender a jornada de trabalho em função dos baixos salários, as empresas acabam permitindo e incentivando uma jornada de trabalho adicional à regida pelas leis trabalhistas, inclusive no período noturno e nos finais de semana. O representante de uma das empresas pesquisadas relata: "eu tenho hoje três baianos aqui que trabalham pra caramba. Inclusive, às vezes, a gente só os coloca para fazer um servicinho diferente pra ver se eles rendem um pouco mais, porque eles rendem..."6.

Esse rendimento normalmente está associado ao trabalho desgastante e exaustivo, com a combinação de uma extensa e intensa jornada de trabalho, como já mencionado, em tarefas repetitivas e que exigem grande esforço físico. Os trabalhadores indicam desgastes físicos e mentais, o que compromete a saúde dos mesmos. Além disso, são nítidas as frustrações frente às expectativas que são criadas quando partem de seus locais de origem em busca de trabalho e melhores condições de vida, visto não conseguirem realizar a tão sonhada e desejada economia.

[...] o trabalho é cansativo, não pára nunca. ${ }^{7}$ 
Humilhação, a pessoa trabalha muito, ganha pouco. Eu tô arrependido, porque eu saí com esperança boa de ajuntar um bom dinheiro aqui, mas desisti, mas o cara se mata semana toda e final de semana para ganhar um pouco também, não vale a pena. ${ }^{8}$

A gente veio porque precisa, eles precisam mais do que a gente. Serviço pesado entendeu? Todo o serviço de obra para mim é pesado. Se fosse assim, um servicinho assim suave que não machucasse muito a gente, aí tinha até como raciocinar, mas o serviço dói, é muito pesado. É bom trabalhar é, mas tem serviço que maltrata muito a pessoa. ${ }^{9}$

As situações descritas acima revelam a exploração da classe trabalhadora e a extrema precarização das relações e condições de trabalho próprias do modo capitalista de produção, ao transformar a força de trabalho em mercadoria. Tal situação se reproduz e se amplia diante da redução do trabalho vivo, aumento do desemprego e flexibilização ou redução de direitos trabalhistas.

Observamos que os trabalhadores se submetem à exploração visto ser a única forma dos destituídos dos meios de produção e subsistência produzirem a sua existência nestas relações sociais. Além disso, são pressionados pelo "exército industrial de reserva", conforme formulação de Marx. "A população trabalhadora, ao produzir a acumulação do capital, produz, em proporções crescentes, os meios que fazem dela, relativamente, uma população supérflua. Esta é uma lei da população peculiar ao modo capitalista de produção" (MARX, 2011, p. 734).

\section{As condições de vida dos migrantes}

Os trabalhadores migrantes vivem em alojamentos junto às obras da construção civil no interior da Universidade Federal de Santa Catarina. Para orientar nossa análise sobre tais condições tomamos como referência as reflexões de Oliveira (1976) sobre a reprodução da população para o capital. Com base em Marx, o autor compreende que a população não pode ser tomada em si, enquanto generalidade, visto que ela se reproduz em determinado modo de produção. A transformação do trabalho em força de trabalho, com base na separação do trabalhador dos meios de produção, estabelece a população para o capital. Nesse sentido, os conceitos para pensar a reprodução humana (mortalidade e fertilidade) ganham "especificidade bumana, colocando-os de pé e unificando-os dialeticamente sob o conceito de 'gasto de trabalho'.” (p. 9) Na medida em que a produção de mais-valia consome força de trabalho e o salário está abaixo do custo de reprodução dos trabalhadores (incluindo moradia e alimentação), apresenta-se uma contradição insolúvel dentro das relações sociais de produção.

A moradia dos trabalhadores migrantes é mais uma faceta da relação capitalista entre empresa e trabalhadores. Quando os trabalhadores chegam à Florianópolis, vão atrás de aluguéis na cidade para se instalarem, principalmente em morros e periferia. Entretanto, a maioria deles acaba por se instalar nos alojamentos dos canteiros de obras que as empresas oferecem, em função do alto custo dos aluguéis na cidade. As empresas têm interesse nos alojamentos junto às obras, visto que os trabalhadores estendem com maior facilidade a jornada e são assíduos no trabalho, não há custo de transporte e alguns ainda fazem a segurança nos canteiros de obras como trabalho gratuito.

As empresas oferecem alojamentos e então eles acabam indo direto no trabalho, procurar uma empresa, as vezes que ofereçam alojamento para não precisarem alugar 
um apartamento fora. Às vezes acho que dá para dizer que dá uma maior assiduidade no trabalho. As vezes até alguém acaba meio que assumindo uma função, como se fosse uma função de extra vigilante, extra oficial, no final de semana eles dão uma olhada na obra. É um meio diferente de cuidar da obra, como sempre tem alguém no local de trabalho, um vigilante extraoficial, a obra não fica abandonada, gera um pouco de segurança, além da assiduidade. ${ }^{10}$

Pelo menos o básico aqui eles têm, tem comida, tem lugar para tomar banho, tem lugar para lavar a roupa. É bem acomodados dentro do quarto, tem até um certo conforto, e tem o segurança do trabalho que sempre está cuidando disso pra gente, Sempre tá olhando, pra gente poder melhorar, a gente sempre está melhorando em alguma coisa. ${ }^{11}$

Os alojamentos compreendem dormitórios, cozinha, banheiros e refeitório. São construções precárias de madeira, sem nenhum conforto, embora as empresas considerem confortáveis. Os quartos abrigam de 4 a 6 trabalhadores e não apresentam janelas, portanto, não há ventilação e iluminação. Alguns contam com uma pequena ventarola que fica no alto da parede normalmente fechada. Os beliches são de madeira rudimentar e não há armários, o que dificulta o armazenamento dos pertences dos trabalhadores. Os banheiros são separados dos quartos, dentro de uma estrutura rudimentar, não possuem armários nem espelhos, em alguns nem cesto de lixo. Nas cozinhas, os armários estão em péssimas condições e as panelas são velhas e amassadas, há falta de gás para cozinhar os alimentos e por isso é usado o fogão a lenha. A responsabilidade pela limpeza e higiene dos espaços é dos trabalhadores e muitas vezes são eles que cozinham o seu próprio alimento. Em função do cansaço e desgaste físico e pela falta de produtos de limpeza (oferecidos pelas empresas) e das condições limitadas dos próprios espaços, estes acabam sendo sujos e fétidos.

Os responsáveis pelas empresas entrevistadas consideram as condições dos alojamentos de ruins a boas, como vimos acima, e dizem que estão sempre se esforçando na melhoria dessas estruturas precárias. É importante considerar que é nesses espaços que os trabalhadores passam a maior parte do tempo, longe de seus locais de origem e familiares. Os espaços são insalubres, com pouca incidência de sol e o ambiente é permeado por brigas e confusões que são provocadas pelo consumo de bebidas alcoólicas. Não há qualquer alternativa de lazer. E os trabalhadores ainda sofrem com a saudade dos familiares e com o período de frio na região sul.

Tal situação se assemelha às condições de vida e de trabalho dos operários no início da industrialização capitalista. O modo de produção capitalista, segundo Engels (2008), se consolidou nas grandes cidades no século XIX, juntamente com o operariado que em condições de pobreza ocupou as regiões periféricas ${ }^{12}$ das cidades. Portanto, os operários ${ }^{13}$ habitavam nos bairros populares que passaram a concentrar um conjunto de pequenas fabriquetas. Por sua vez, os burgueses ocuparam as regiões centrais que, além de mais atrativas, possuíam maiores recursos. "É certo ser frequente a miséria abrigar-se em vielas escondidas, embora próximas aos palácios dos ricos” (ibid, p. 70).

Todas as grandes cidades têm um ou vários "bairros de má fama" onde se concentra a classe operária. [...], em geral, é-lhe designada uma área à parte, na qual, longe do olhar das classes mais afortunadas, deve safar-se, bem ou mal, sozinha. Na Inglaterra, esses "bairros de má fama" se estruturam mais ou menos da mesma forma que em todas as cidades: as piores casas na parte mais feia da cidade; quase sempre, uma longa fila de construções de tijolos, de um ou dois andares, eventualmente com porões habitados e em geral dispostas de maneira irregular. Essas pequenas casas de três ou quatro cômodos e cozinha chamam-se cottages e normalmente constituem em toda a 
Inglaterra, exceto em alguns bairros de Londres, a habitação da classe operária (ENGELS, 2008, p. 70).

De acordo com Perrot (1988), a moradia operária urbana do século XIX tem grande mobilidade no uso do espaço e isso vale para todas as classes. Pagar o mínimo possível pelo alojamento é ambição dos operários, que na maioria das vezes vem de regiões rurais onde ele não custa nada. Sendo assim, há deslocamentos constantes das famílias que buscam fugir a terem que enfrentar os "abutres", proprietários exigentes no valor e no prazo do pagamento do aluguel. "O mundo operário da época ainda é móvel, quase nômade” (p. 105). As migrações temporárias, principalmente os operários da construção acentuam essa mobilidade, sobretudo os pedreiros que têm na cidade apenas uma moradia precária, uma vaga ou um quarto mobiliado da qual esperam apenas um abrigo para a noite (p. 109).

Suas habitações são chocas miseráveis; vários membros da família dormiam juntos sobre palha, ou até mesmo chão... sua alimentação consistia geralmente de batatas secas, e eles... tinham de satisfazer com uma refeição fruga por dia. [...] Às vezes, conseguiam um arenque, um pouco de leite, mas nunca comiam carne, a não ser no natal, na páscoa e no carnaval (THOMPSON, 1987, p. 328).

Segundo Marx (2011, p. 775), “quanto mais rápido se acumula capital numa cidade industrial ou comercial, tanto mais rápido é o afluxo de material humano explorável e tanto mais miseráveis as habitações improvisadas dos trabalhadores". Portanto, "o empresário trata toda a colônia como se ela estivesse acampada no local e não residisse ali” (p. 786). Quando os empreendimentos envolvem muito dispêndio de capital, o próprio empresário fornece a seu exército barracos de madeira, cujo aluguel é descontado dos salários ou construções semelhantes, verdadeiras aldeias improvisadas, sem qualquer preocupação de ordem sanitária e fora do controle das autoridades locais, pois estas significam rentabilidade para o empreiteiro. O capital não tem a menor cerimônia em justificar as condições perigosas e degradantes a que estão submetidos os trabalhadores, seja nas atividades de trabalho ou no lar, porque renuncia qualquer possibilidade de proteger o trabalhador, quer na ventilação de seus barracos ou na segurança de suas atividades.

Com relação à alimentação dos trabalhadores, as empresas afirmam garantir de três a quatro refeições diárias em um ambiente agradável.

Igual que nessa obra aqui eu venho de 15 em 15 dias aqui, né. Eu vejo a cozinha já limpa, organizada. Eu vejo o banheiro limpo organizado. Nós temos uma alimentação boa, com qualidade, porque eu também cuido disso, enfim nós temos que dar um ambiente bom, agradável, aonde eles não vão ter nenhum tipo de problema, de doença, de mal estar por estar vivendo na obra. Três refeições, que são o café da manhã, almoço, daí tem mais o café da tarde e o jantar. É assim oh, na parte da manhã é dado esse café assim já normal margarina, mousse, que é o normal né, o leite tal. E aí já é o almoço já normal né, as vezes é feito o frango, as vezes é feito carne de gado. Tem macarrão, arroz, feijão, né, que é o básico. O básico né, daí é claro se tem alguém que queira algo diferente, nós temos a geladeira, nós temos a nossa kit despensa, essa pessoa tem o direito de comprar algo diferente que ele vai poder ${ }^{14}$

Eles dão carne, tem um freezer cheio de carne, arroz, feijão. Eles fazem a comida lá, tem um cozinheiro que trabalha lá.15

$\mathrm{Na}$ avaliação de alguns trabalhadores, a alimentação é péssima e frequentemente há falta de alimento. Essa situação dificulta inclusive o trabalho e acaba por afetar a saúde dos trabalhadores. Alguns consideram a alimentação de baixa qualidade e outros não reclamam. 
Hum, é péssima aqui [...] é só um arroz, um macarrão de rosca e feijão e galinha só. Todo dia. De manhã café, meio dia o almoço e de noite a janta. ${ }^{16}$

É descontado do salário. ${ }^{17}$

Alimentação eu vim pra aqui informado que ela [a empresa] dá. Aí ela compra, mas tem dia mesmo, sexta feira pra ela mandar já trazer, mas ela não mandou trazer nada de lá para cá, não. Daí eu passei três dia e nada. Daí se eu não compro o meu eu ia comer puro por três dias ai. Aí fica sem comer, é melhor a gente ficar lá na Bahia mesmo, porque a gente ganha mais. Eu vim pra aqui porque dava comida. (...) E a pessoa toma prejuízo, quando vai pagar a comida. Teve um tempo aí que quando eu fui pagar a comida, teve um mês aí que eu fiquei só com $\mathrm{R} \$ 800,00 .{ }^{18}$

Tem vezes que eu vou trabalhar sem café, tem dias que eu passo, 10 dias, 5 dias sem tomar café e não tem ninguém aí para me ajudar. O cara dá fraqueza! Quem tem café toma, quem não tem, não toma [risos]. (...) Aí cozinha uma comida aí no fogão, bujão tem, só que eles não enchem para nós. Problema de saúde, quando eu vou trabalhar, dá 1h e meia, o cara dá uma tontura, quando o sol tá muito quente, aí dá uma tontura, a altura dá tontura, pra subir. ${ }^{19}$

Observamos mais uma vez a discrepância entre o depoimento dos responsáveis pelas empresas e o dos trabalhadores. Os primeiros garantem oferecer três a quatro refeições diárias em ambiente agradável. Já os trabalhadores denunciam a irregularidade na entrega dos alimentos, a insuficiência e até mesmo ausência de comida, baixa qualidade, necessidade de cozinhar no fogão a lenha dada a falta de gás, bem como o custo dos alimentos fornecidos pelas empresas.

Com relação às poucas horas vagas, a grande maioria dos trabalhadores fica reclusa nos alojamentos e são várias as razões para isso, entre elas os baixos salários e a necessidade de economizar, privando-se de qualquer tipo de consumo. Como já afirmado, alguns trabalhadores são incentivados e incumbidos pelas empresas a cuidar dos canteiros de obras nos finais de semana. No mais, eles conversam entre si, dormem, jogam dominó e consomem bebidas alcoólicas. Aproveitam também para realizar contato telefônico com seus familiares e se organizam em suas necessidades individuais, como lavar roupas e limpar seus aposentos.

Abaixo, os trabalhadores relatam sobre o "tempo livre" e porque se mantêm nos alojamentos mesmo aos finais de semana:

Só aqui, não saio para lado nenhum. Porque não tenho conhecimento de nada, não
conheço ninguém aqui, não conheço a cidade, também tem discriminação assim, a
gente tá passando e o pessoal diz peão de obra, não dá nem bom dia, vira a cara. ${ }^{20}$
Eu não tenho, o lazer daqui, a gente trabalha direto. Aqui eu não saio para canto
nenhum. A gente não sai porque a gente trabalha de segunda a segunda. Amanhã a
gente trabalha, domingo a gente trabalha até ao meio dia. E de tarde que é a hora para a
gente relaxar um pouquinho, a gente vai lavar a roupa. Aí não tem como. As vezes tem
festa aqui, tem uma festinha sempre aqui, mas se a gente for sair para uma festa aqui, o
outro dia a gente está morto de cansado para trabalhar. ${ }^{21}$
Se diverte nada. Não tem divertimento aqui não, divertimento é dentro de casa, no
barraco aí direto..$^{22}$ Segundo Engels (2008), o cruel efeito da situação precária dos operários e migrantes nas cidades produziu dois caminhos: a revolta interior e exterior contra a burguesia ou então o alcoolismo e a degradação. "A burguesia, ao mesmo tempo em que acumulou de penas e sofrimentos, só lhe deixou dois prazeres - a bebida e o sexo - e a consequência é que os trabalhadores concentram aí todas as suas paixões, entregando-lhes a eles com excessos e de maneira desenfreada" (p. 166). Os operários são postos pela burguesia em uma situação que não convém nem aos animais, debilitando sua saúde física e mental, 
sendo expostos a um trabalho árduo, restando-lhes poucos e miseráveis prazeres materiais. "Uma classe de cuja instrução ninguém cuida" (p. 167).

\section{A escolarização dos trabalhadores migrantes}

A mobilidade dos trabalhadores tem sido uma constante, motivada fundamentalmente pelo trabalho. Nesse processo, a educação acaba sendo afetada e muitos são os que abandonam a escola muito cedo para poderem trabalhar. A literatura educacional crítica de base marxista indica forte relação entre as condições de vida, trabalho e escolarização.

Constatamos, a partir das entrevistas realizadas, que todos os entrevistados estão fora da escola e/ou tiveram que abandoná-la muito cedo para poderem trabalhar. No seu cotidiano, no interior de uma universidade, paradoxalmente a escola está muito distante. Os trabalhadores possuem baixa escolarização, $78 \%$ tem o ensino fundamental incompleto e admitem terem dificuldade na leitura, $11 \%$ completaram o ensino fundamental e $11 \%$ tem o ensino médio incompleto. Também identificamos que nenhum dos seus pais completaram o ensino fundamental, alguns não sabem ler e tiveram pouca frequência à escola.

Abaixo, os trabalhadores comentam sobre as razões do abandono da escola:

Ou para de estudar ou sobrevive, tem que trabalhar, não tem como..$^{23}$

Eu não sei ler, tem que saber ler para fazer o curso, né? Não sei ler direito. ${ }^{24}$

Por falta de dinheiro, para ajudar minha família. Minha família é gente humilde, é pobre, é gente pobre, aí tive que largar os estudos, eu, meu pai, ele largou primeiro que eu. Saiu por aí fazer a vida e eu estou fazendo a mesma coisa, para ajudar minha família. ${ }^{25}$

Oh! trabalho muito, eu estudava de noite, trabalhava de dia e estudava de noite. Quando eu ia para a escola eu só ia cochilar, aí eu disse, eu vou sair, não dá para ficar, eu estou muito cansado, só pra quem tem tempo mesmo. Aí não teve jeito, tive que sair, porque eu trabalhava numa firma que eu acordava as 3 horas da manhã, aí eu perdia o carro. Se eu perdesse o carro, perdia o dia. Aí, eu ia para a escola, a professora falava e eu dormindo. ${ }^{26}$

Compreendemos que o processo de expropriação dos trabalhadores se reflete na escolarização e qualificação para o trabalho, sendo desencadeado na origem e estendendo-se à atualidade na sociedade capitalista. Harvey (2016), com base em Marx, analisa que a complexidade e sinuosidade dos sistemas de produção possibilitou que o capital sempre buscasse uma força de trabalho educada, disciplinada, subordinada e flexível diante das exigências e demandas do modo de produção capitalista. As atuais demandas de produtividade tem exigido para uma parcela da força de trabalho maior qualificação e para uma grande massa apenas treinamento para o trabalho. Fontes (2016) assinala que a educação responde sempre a dois movimentos contraditórios: de um lado, a formar "trabalhadores" de níveis diversos e, de outro lado, a sociedade capitalista é impelida a responder às exigências de massas crescentes de trabalhadores que aspiram (e reivindicam) a inúmeras saídas pela educação. Há ausência efetiva de acesso à escola para a maioria da "classe trabalhadora" e também diferenças substantivas na oferta da educação nos percursos escolares para a burguesia e para a classe trabalhadora.

No caso dos estudantes migrantes, Vendramini (2017, p. 429) aponta que estes, ao se deslocarem, enfrentam diversos problemas, como a interrupção do percurso escolar, defasagens idadesérie geradas pela frequência insuficiente, dificuldade de acompanhamento dos conteúdos, de adaptação à 
escola, mudança de turno e de escola, transferência do ensino regular para a Educação de Jovens e Adultos. Os jovens também vivenciam preconceitos na escola. Essa realidade é expressão de múltiplas determinações, entre elas e não menos importante, a necessidade de inserção precoce no trabalho.

$\mathrm{Na}$ atualidade, o desmantelamento da escola pública colabora com o afastamento dos estudantes trabalhadores, aprofundando ainda mais a dualidade do sistema escolar brasileiro.

\section{Considerações finais}

Constatamos que os trabalhadores migrantes da construção civil da UFSC deslocaram-se de seus locais de origem em busca de trabalho, melhores salários e condições de vida. No novo local de trabalho ficam submetidos a uma situação de degradação, precariedade, insegurança e exploração do trabalho, acrescidas das condições insalubres de moradia, bem como alimentação insuficiente e irregular. Os trabalhadores vivenciam uma exaustiva jornada de trabalho, com exposição diária às intempéries climáticas da região sul, seja pelo calor excessivo nos períodos de verão ou pelos dias frios e chuvosos de inverno.

Tais trabalhadores são a expressão de uma crescente população supérflua que se torna completamente disponível ao capital, em qualquer lugar e em quaisquer condições de trabalho. Da gênese à contemporaneidade do modo de produção capitalista, a classe trabalhadora tem estado sob controle e subordinação ao capital.

A situação da classe trabalhadora foi denunciada por Engels nos anos 1845 na Inglaterra, bem como por Marx, Thompson e Perrot (esta relatando o caso francês). Tal situação não se alterou, pelo contrário, vem se agravando cada vez mais e produzindo barbárie. Enquanto vivermos regidos pelo modo de produção capitalista, a lógica da acumulação e expansão do capital versus expropriação e exploração da classe trabalhadora permanecerá como regra. O que se passa na Inglaterra no século XIX alcança os outros continentes e países ao longo do século XX. No século XXI "assistimos" a exércitos de migrantes cruzando fronteiras (nacionais e internacionais) expulsos por conflitos e guerras, perseguições, crimes ambientais, desemprego e fome.

Observamos no caso específico neste artigo as contradições que permeiam a relação entre as empresas terceirizadas da construção civil que atuam no interior da universidade e os trabalhadores migrantes. As empresas veem nos migrantes as condições para o trabalho dócil e de baixo custo. Os trabalhadores, por sua vez, necessitados do trabalho e da moradia, submetem-se às longas jornadas e ao trabalho pesado e desgastante, bem como à vida nos barracos insalubres e isolados. É a expressão do antagonismo de classes e da necessidade de superação das relações sociais assentadas na expropriação e na exploração.

\section{Referências}

ANTUNES, R. A sociedade da terceirização total. Revista da ABET, v. 14, n.1, Jan-Jun. 2015. 
ENGELS, F. A situação a classe trabalhadora na Inglaterra. São Paulo: Boitempo, 2008.

FONTES, V. Formação dos trabalhadores e luta de classes. Trabalho Necessário, v. 14, n. 25, 2016.

HARVEY, D. 17 contradições e o fim do capitalismo. São Paulo: Boitempo, 2016.

HARVEY, D. O novo imperialismo. 8.ed. Trad. de Adail Sobral e Maria Stela Gonçalves. São Paulo: Edições Loyola, 2014.

MARX, K. O capital: crítica da economia política. Trad. de Reginaldo Sant`Anna - livro I. 25. ed. Rio de Janeiro: Civilização Brasileira, v. 2, 2011.

OLIVEIRA, F. A produção dos homens: notas sobre a reprodução da população sob o capital. Estudos Cebrap. São Paulo, n. 16, p. 5-25, 1976.

PERROT, M. Os excluidos da história: operários, mulheres e prisioneiros. Tradução Denise Bottmann. Rio de Janeiro: Paz e Terra, 1988.

SILVA, M. A. M. Destinos e trajetórias de camponeses migrantes. In: ABEP. ANAIS DO VIII ENCONTRO NACIONAL DE ESTUDOS POPULACIONAIS. 1992. 161-186 p. Disponível em: < http://www.abep.nepo.unicamp.br/docs/anais/pdf/1992/T92V03A09.pdf>. Acesso em: 11 nov. 2015.

THOMPSON, E. P. A formação da classe operária inglesa. Tradução Renato Bussato Neto, Claudia Rocha de Almeida. Rio de Janeiro: Paz e Terra, 1987.

VENDRAMINI, C. R. Jovens migrantes diante do desafio de trabalhar e estudar. Revista Contrapontos. Itajái, v. 17, n. 3, Jul-Set 2017.

\section{Notas}

1 Mestre em Educação. UFSC. Orcid: https://orcid.org/0000-0002-4057-2535 Email: janaamora@hotmail.com

2 Professora na Universidade Federal de Santa Catarina. Departamento de Estudos Especializados em Educação. Centro de Ciências da Educação. Orcid: http://orcid.org/0000-0001-9600-2868 Email: celiavendram@gmail.com

${ }^{3}$ Entrevistado 10, técnico de edificação do trabalho da empresa Progredior.

${ }^{4}$ Entrevistado 12, auxiliar de engenheiro civil da empresa Predicom/Salver.

${ }^{5}$ Entrevistado 4, pedreiro da empresa Progredior, 22 anos, $7^{\circ}$ ano do Ensino Fundamental.

${ }^{6}$ Entrevistado 14, técnico de Segurança do trabalho da empresa Progredior.

7 Entrevistado 1, pedreiro da empresa Salver, 27 anos, $1^{\circ}$ ano do Ensino Médio.

8 Entrevistado 4, pedreiro da empresa Progredior, 22 anos, $7^{\circ}$ ano do Ensino Fundamental.

${ }_{9}$ Entrevistado 7, pedreiro da empresa Progredior, 36 anos, $5^{\circ}$ ano do Ensino Fundamental.

${ }^{10}$ Entrevistado 11, engenheiro civil da Empresa Salver.

${ }^{11}$ Entrevistado 14, técnico de segurança do trabalho da Empresa Progredior.

${ }^{12}$ Segundo Perrot (1988, p. 119), esse ordenamento periférico para o operário não passa de uma alternativa desfavorável. "A ambição operária se inscreve no coração das cidades. É lá no centro de tudo, que se tem de viver e morar".

13 Sobre as condições físicas do operário, Engels (2008) cita um médico que examina recrutas: “Os operários são baixinhos, magros e dispõem de diminuta força física. Muitos deles apresentam deformações na caixa torácica ou na coluna vertebral” ( $\mathrm{p}$. 234).

${ }_{14}$ Entrevistado 13, técnico em segurança do trabalho da empresa Salver.

15 Entrevistado 12, auxiliar de engenheiro da empresa Predicom/Salver.

${ }^{16}$ Entrevistado 4, pedreiro da empresa Progredior, 22 anos, $7^{\circ}$ ano do Ensino Fundamental.

${ }^{17}$ Entrevistado 1, pedreiro da empresa Salver, 27 anos, $1^{\circ}$ ano do Ensino Médio.

${ }^{18}$ Entrevistado 8, pedreiro da empresa Salver, 25 anos, $4^{\circ}$ ano do ensino Fundamental (não sabe ler).

${ }^{19}$ Entrevistado 7, pedreiro da empresa Progredior, 36 anos, $5^{\circ}$ ano do Ensino Fundamental.

${ }^{20}$ Entrevistado 4, pedreiro da empresa Progredior, 22 anos, $7^{\circ}$ ano do Ensino Fundamental.

${ }^{21}$ Entrevistado 7, pedreiro da empresa Progredior, 36 anos, $5^{\circ}$ ano do Ensino Fundamental.

22 Entrevistado 8, pedreiro da empresa Salver, 25 anos, $4^{\circ}$ ano do Ensino Fundamental (não sabe ler).

${ }^{23}$ Entrevistado 1, pedreiro da empresa Salver, 27 anos, $1^{\circ}$ ano do Ensino Médio.

${ }^{24}$ Entrevistado 8, pedreiro da empresa Salver, 25 anos, $4^{\circ}$ ano do Ensino Fundamental (não sabe ler). 
${ }^{25}$ Entrevistado 4, pedreiro da empresa Progredior, 22 anos, $7^{\circ}$ ano do Ensino Fundamental.

${ }^{26}$ Entrevistado1, pedreiro da empresa Salver, 27 anos, $1^{\circ}$ ano do Ensino Médio.
Recebido em: 31/07/2019

Aprovado em: 16/09/2019 